\title{
Alcohol Dependence Syndrome Among Older Adults Attending Psychiatry OPD of a Private Hospital in Western Region of Nepal
}

\author{
Khattri JB, ${ }^{1^{*}}$ Poudel BM, ${ }^{2}$ Godar ST, ${ }^{3}$ Ramesh $K,{ }^{1}$ Chakrabortty PK, ${ }^{1}$ Thapa BB $^{4}$ \\ ${ }^{1}$ Department of Psychiatry, Manipal Teaching Hospital, Pokhara, Nepal, ${ }^{2}$ Vyas Nagar Hospital, Damauli, \\ ${ }^{3}$ Department of Ophthalmology, Manipal Teaching Hospital, Pokhara, Nepal, \\ ${ }^{4}$ Depatment of Internal Medicine, Western Regional Hospital, Pokhara, Nepal
}

\begin{abstract}
*Corresponding Author:
Dr. Jai Bahadur Khattri, MBBS, MD

Assistant Professor, Department of Psychiatry

Manipal Teaching Hospital, Pokhara, Nepal

Email:jai_khattri@yahoo.com

\section{Citation}

Khattri JB, Poudel BM, Godar ST, Ramesh K, Chakrabortty PK, Thapa BB. Alcohol dependence syndrome among older adults attending psychiatry OPD of a private hospital in western region of Nepal. Nepal Journal of Medical Sciences. 2012; 1(1): 39-41.
\end{abstract}

\begin{abstract}
Background: Alcohol use disorders in elderly people are common and associated with considerable morbidity. The objective is to estimate the prevalence of alcohol dependence syndrome among elderly patients attending psychiatric outpatient department of a private hospital in Western region of Nepal.
\end{abstract}

Methods: A total of 80 elderly patients aged 65 years and above who attended the psychiatry outpatient department of Fewa City Hospital and Research Centre, Pokhara, Nepal were included in the study. A semistructured Performa was used to record the sociodemographic variables and the diagnosis was made according to ICD-10 Diagnostic Criteria for Research.

Results: Five percent of the samples were diagnosed with alcohol dependence syndrome. The male to female ratio was 3:1.

Conclusion: Results show high rates of alcohol dependence among the elderly population attending the outpatient department of a private hospital in Western Region of Nepal.

Keywords: Alcohol dependence syndrome; older adults; psychiatric OPD

\section{Background:}

$\mathrm{S}_{\mathrm{i}}$ although the scope of the problem has only been appreciated recently. ${ }^{1,2}$ The ageing of population's worldwide means that the absolute number of older people with alcohol use disorders is on the increase, and health services need to improve their provision of age appropriate screening and treatment methods and services.

The media attention and public health initiatives related to alcohol use disorders tend to usually focus on younger age groups. ${ }^{3-5}$ Furthermore, in elderly people they are often under detected and misdiagnosed ${ }^{6}$ as screening instruments and diagnostic criteria are geared towards younger people. Denial of substance abuse is also common in affected people of all ages, but may be exaggerated in elderly patients because of memory problems, pessimism about recovery, and shame based on a belief that alcohol abuse is immoral.

The elderly patients with alcohol problems also have high rates of physical and psychiatric illness, they probably will be frequent users of health facilities and fuel concerns about the rising costs of medical care. Also, because most of the previous studies have focused on younger adults and for policymakers and elder-care practitioners to anticipate the needs of alcohol problem of older adults, the exact data about alcohol problems in Nepalese population must first be established. So, the aim of the study is to estimate the prevalence of alcohol dependence among geriatric patients attending outpatient departments of a private hospital in western region of Nepal. 


\section{Methods:}

Cases were selected above 65 years attending the Psychiatry Out-Patient Departments of Fewa City Hospital and Research Centre, Pokhara, Nepal. This study has been designed as a cross-sectional study and sample size being 80 . The study was conducted from June 2009 to June 2011. The consent was taken from the patients or patient's relatives. The consent was taken from the relatives of the patients if there is suspicion of cognitive decline or if the patient is unable to give the consent. The patients with acute medical/ surgical emergency conditions and those who did not give the informed consent were excluded from the study. The rapport was established with the patient and the relatives to get enough information.

Self-designed semi-structured Performa is prepared to obtain the socio-demographic characteristics of the patients. The detailed history is taken from the patient and an informant. The information was collected carefully about the history of alcohol from the patient and also from the relatives. Detailed physical examination and mental state examination were undertaken. The clinical diagnosis was made according to ICD-10 Diagnostic Criteria for Research (ICD-10 DCR). ${ }^{8}$ The distribution of the variables was presented in percentages. Data was analyzed by Epi Info 6 version.

\section{Results:}

Table 1 shows the distribution of respondents on the basis of sex. $57.5 \%$ of the patients were male and remaining was female.

The table 2 shows the sex distribution of respondents on the basis of diagnosis of alcohol dependence syndrome according to ICD-10 DCR. The data shows that there is a history of alcohol dependence in 4 cases $(5 \%)$ and in 76 patients (95\%), no history of alcohol was elicited. Out of 4 cases, 3 were male and 1 female. The data is not statistically significant.

Table 1: Distribution of respondents on the basis of sex. $(\mathbf{n}=\mathbf{8 0})$

\begin{tabular}{lcccc}
\hline \multirow{2}{*}{ Respondents } & Male & Female & \multicolumn{2}{c}{ Total } \\
& N (\%) & N (\%) & N & \% \\
\hline Total & $46(57.5)$ & $34(42.5)$ & 80 & 100 \\
\hline
\end{tabular}

Table 2: Sex distribution on the basis of diagnosis of Alcohol dependence syndrome according to ICD-10 DCR. $(\mathbf{n}=\mathbf{8 0})$

\begin{tabular}{lccc}
\hline \multicolumn{1}{c}{ Sex } & \multicolumn{2}{c}{ ADS } & \multirow{2}{*}{ P value } \\
& Yes (\%) & No (\%) & \\
\hline Male & $3(6.5)$ & $43(93.5)$ & \multirow{2}{*}{ Female } \\
\hline
\end{tabular}

\section{Discussion:}

Elderly alcoholics manifest the same signs of alcohol dependence as younger adults; however, it is more likely in older adults that the biomedical complications of heavy drinking will bring alcohol problems to clinical attention. Severe cases may mimic other geriatric medical illness, when such features as falls, confusion, dehydration, malnutrition, myopathy, incontinence, or traumatic injury are evident.

The community 12-months prevalence rate for alcohol dependence declines with age from peaks in young adulthood to about 1 to 2 percent in people aged 55 years and older, but, because of associated medical and psychiatric problems, rates of current problem drinking among elderly people in clinical settings are much higher, varying from 4 to 23 percent in representative surveys. ${ }^{9}$ In general, the prevalence for elderly inpatients is higher than for elderly people in the community, with estimates of $14 \%$ for patients in emergency departments, $18 \%$ for medical inpatients, and $23-44 \%$ for psychiatric inpatients. ${ }^{10}$ However, the most prevalence studies have been carried out in North America, and results may not be generalized to other cultures. ${ }^{11}$

The present study found the prevalence rate of alcohol dependence to be 5 percent (Table 2) according to ICD-10 Diagnostic Criteria for Research. Koirala et $\mathrm{al}^{12}$ found that only 1.3 percent of the elderly patients were using alcohol at the dependent level. This may due to the fact that the study by Koirala et al $^{12}$ was done in the university hospital setting at Kathmandu and the patients who were well motivated to leave alcohol visits this central psychiatric setting. However, the present study was done in the nursing home setting which is accessible and also, the elderly who were suffering from the medical complications of alcohol were more likely to visit these settings. Study by Jones et $\mathrm{al}^{13}$ also found the prevalence rate of $4 \%$ in general medical outpatient setting.

The male to female ratio was found to be 3:1 in the present study. Atkinson also documented that men are between two and six times more likely than women to have clinically documented alcohol problem. ${ }^{14}$ Edwards et a ${ }^{15}$ also noted the female rate of problem drinking significantly below the male rate. This assumption could further be enhanced by the lack of socio-cultural acceptance for use of alcohol among female in the Nepalese population.

\section{Conclusion}

The present finding suggests that substantial proportion of elderly subjects attending the psychiatry outpatient department suffers from alcohol dependence syndrome. A careful history of current and lifetime alcohol consumption should be ascertained with every elderly patient, with a 
collateral history from a relative or spouse if possible. The higher prevalence of alcohol dependence necessitates about early intervention since it has deleterious interaction with physical health. Accurate and early diagnosis and adequate treatment of alcohol dependence favors a good prognosis.

\section{References:}

1. Atkinson RM, Ganzini L, Bernstain MJ. Alcohol and substance-use disorders in the elderly. In: Barren JE, Sloane B, Cohen GD, ed. Handbook of mental health and aging. $2^{\text {nd }}$ ed. New York: Academic Press, 1992:515-55.

2. Liberto JG, Aslin DW, Ruskin PE. Alcoholism in older persons: a review of the literature. Hosp Community Psychiatr 1992;43:975-84.

3. Strategic Task Force on Alcohol. Strategic Task Force on Alcohol Interim Report. Dublin: Department of Health and Children, Ireland, 2002.

4. Reid MC, Anderson PA. Geriatric substance use disorders. Med Clin North Am 1997;81:999-1016.

5. CNN, Associated Press, Reuters. Alcohol named Europe's youth killer. www.cnn.com/2001/ HEALTH/02/19/deaths.alcohol/

6. Khan N, Davis P, Wilkinson TJ, et al. Drinking patterns among older people in the community: hidden from medical attention? N Z Med J 2002;115:72-5.

7. Lakhani N. Alcohol use amongst community-dwelling elderly: a review of the literature. J Adv Nurs 1997;25:1227-32.
8. World Health Organization. The ICD-10 Classification of Mental and Behavioral disorders (Tenth Revision): Diagnostic Criteria for Research; Geneva, 1992.

9. Atkinson RM. Substance abuse. In: Coffey CE, Cummings JL, ed. Textbook of geriatric neuropsychiatry. $2^{\text {nd }}$ ed. Washington DC: American Psychiatric Press, 2000 .

10. Goldstein MZ, Pataki A, Webb MT. Alcoholism among elderly persons. Psychiatr Serv 1996;47:941-3.

11. Johnson I. Alcohol problems in old age: a review of recent epidemiological research. Int J Geriatr Psychiatry 2000;15:575-81.

12. Koirala NR, Nepal MK, Sinha UK, et al. Geriatric Psychiatry: Socio-demographic characteristics and diagnostic profile among senior citizens attending the psychiatric outpatient department of a tertiary health care facility in Nepal. Journal of Institute of Medicine 2000;22:221-226.

13. Jones TV, Lindsey BA, Young P, et al. Alcohol consumption patterns in an elderly ambulatory care population. Poster presented at the annual meeting of the American Geriatrics Society, Washington DC, November 1992.

14. Atkinson RM. Aging and alcohol use disorders: diagnostic issues in the elderly. Int Psychogeriatr 1990;2:55-72.

15. Edwards G, Hawker A, Hensman C, et al. Alcoholics known or unknown to agencies: epidemiological studies in London suburb. Br J Psychiatry 1973;123:169-83. 